\title{
International HRM: national business systems, organizational politics and the international division of labour in MNCs
}

\author{
Tony Edwards and Sarosh Kuruvilla
}

\begin{abstract}
In this paper we address a key issue that dominates international HRM research. namely the global-local question. The question concerns how multinationals can or should balance the pressures to develop globally standardized policies with the pressures to be responsive to the peculiarities of the local context. In our view, three important conceptual weaknesses have restricted research progress in this field: the inadequate conceptualization of national effects, which results in culture being used as an unsatisfactory 'catch-all' for national differences; the lack of attention to the influence of internal organizational politics: and the absence of focus on the internal division of labour within MNCs. We discuss the ways in which these weaknesses can be addressed and the implications of these alternative concepts.
\end{abstract}

Keywords Multinationals: institutions; organizational politics; value chains.

\section{Introduction}

In a review of 20 years of research on the management of human resources in international and comparative perspective, Clark et al. (1999) concluded that the subject was 'running on the spot'. They highlight numerous weaknesses such as the narrow and ethnocentric focus of the research, fragmentation in basic explanatory frameworks. numerous methodological problems, an over-reliance on deductive approaches and, in particular. the inability of research to articulate the precise cultural or institutional features that underlie cross-national differences. Given that they focus on the articles published in the best journals in the field between 1975 and 1995, their finding that most studies 'fail to offer an integrated explanation for their results' (1999: 530) is a damning indictment of the field of international HRM (IHRM).

In this paper we focus on one narrow question within the IHRM field, namely the global-local question. This question concerns how multinational corporations (MNCs) balance the pressures to develop globally integrated HR policies on the one hand while trying to adapt to local pressures on the other. One aspect of this research has been largely analytical, seeking to describe and assess the nature of these pressures, while a second has had a prescriptive focus, offering frameworks to help managers take decisions in this area. This sub-area of IHRM has been the subject of a review by De Cieri and Dowling (1999: 316) who concluded that research is largely 'atheoretical' or 'monotheoretical' corresponding to Pfeffer's (1993) notion of a low level of paradigm development.

Tony Edwards. Senior Lecturer. Department of Management, King's College London, 150 Stamford Street. London SEI 9NH. UK. Sarosh Kuruvilla. Professor. Department of Industrial and Labor Relations, Cornell University. 
Given that research on this sub-field of IHRM has continued to grow significantly since the above-mentioned reviews were published, we first briefly review the dominant issues and findings in recent research. Although some progress has been made, we find that research has not satisfactorily addressed the critical theoretical and practical questions in the field. We then discuss three key conceptual issues not addressed in the mainstream IHRM literature that in our view have restricted research progress. These are: the inadequate conceptualization of national effects, which results in culture being used as an unsatisfactory 'catch-all' for national differences; the lack of attention to the influence of internal organizational politics within MNCs; and the neglect of the variety of ways in which MNCs construct an internal division of labour, a perspective highlighted in the global value chain literature. To conclude, we discuss the implications of adopting new concepts in addressing the global-local question.

\section{Themes and weaknesses in the literature}

The dominant theme in the literature on HRM in MNCs has been the global-local question. A key tension that MNCs face, it is commonly assumed, is how to balance the pressures for globally standardized policies across their operations with the need to be responsive to local (national) conditions. The highly variegated literature in this field falls into two broad categories, conceptual models of IHRM and empirical studies of MNCs, with the latter only rarely used to advance the former. There is considerable variation in the nature of the empirical work, and we provide a listing of illustrative studies and their conclusions in Table 1.

Most conceptual models provide grounds for expecting MNCs to adopt a global element to the way they manage their international workforces. One basis for a uniform global approach is to secure benefits from co-ordinating and integrating their various units. Those who emphasize these benefits diverge in their discussions of how MNCs coordinate and integrate their various units, and in the extent to which integration and co-ordination requires globally uniform HRM to be moderated by the adaptation of HRM to variable local environments (Schuler et al., 1993; De Cieri and Dowling, 1999). However, the common claim is that individual MNCs should pursue some degree of uniformity in order to ensure that their HR practices across countries are consistent with, and contribute to, a global business strategy.

Another source of pressure for global uniformity is the competitive need for MNCs to learn lessons across their operations by diffusing practices that may enhance efficiency in other parts of their operations. Indeed, this was the idea behind the work of many economists in explaining why firms expand into other countries. For instance, an approach known as 'internalization' stressed the competitive advantage the firms derive from transferring knowledge and expertise across borders (e.g. Buckley and Casson, 1976). Of more direct relevance for IHRM, Taylor et al. (1996: 960) draw on a resource-based perspective to argue that practices and strategy in MNCs should be constructed around specific organizational competencies that are critical for securing competitive advantage in a global environment'. This can take the form of spreading practices from the home country to foreign subsidiaries; as Bird et al. (1998: 162) put it, a home management system can represent a distinct resource or competence for the firm, leading to the system being 'transferred to overseas ventures as a way of duplicating that advantage'. However, 'worldwide innovation' (Bartlett and Ghoshal, 1998) can also take the form of tapping the diverse range of practices that a multinational experiences in different countries. For instance, Taylor et al.'s model of strategic international HRM considers that the transfer of HRM policies and practices 
Table 1 Some illustrations of empirical studies examining the global-local issue

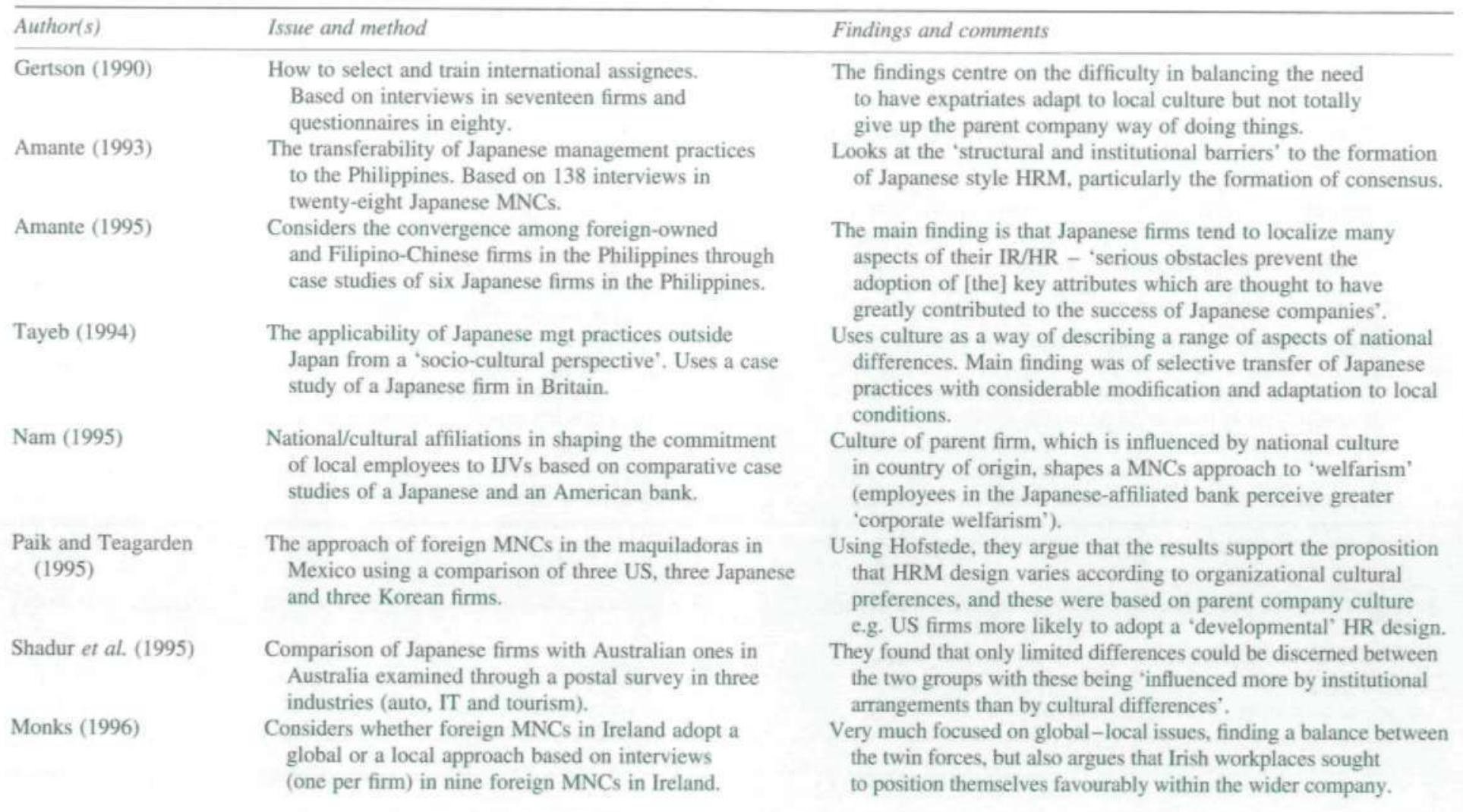


Table 1 (Continued)

\begin{tabular}{lll}
\hline Author(s) & Issue and method & Findings and comments \\
\hline Ding etal (1997) & Considers the extent of HQ control over HR policies & Finds some evidence that MNCs have moved away from practices
\end{tabular}

Ding et al. (1997) Considers the extent of HQ control over HR policies in foreign-owned firms in the Shenzen region of China based on a postal survey of 158 firms.

Turner et al. (1997)

Gill and Wong (1998)

Tayeb (1998)

Ngo et al. (1998)

Bae et al. (1998)

Horwitz and Smith (1998)

Wasti (1998)
Role of MNCs in introducing new forms of employment practices in Ireland, based on a survey of MNCs and local firms.

Examines the extent to which Japanese MNCs employ home-country practices in Singapore based on a survey of employees in 32 firms.

Considers the extent to which MNCs take a global or local approach to HRM through a case study of an American MNC in Scotland.

Effect of country of origin on HR and on firm performance through a postal survey of US. British, Japanese and local firms in Hong Kong. Examines home and host country effects through a survey of foreign and indigenous firms in Korea and Taiwan.

A comparison of the use of flexible work practices between South African and foreign-owned firms in South Africa.

The ease of implementing American and Japanese practices in Turkey based on a survey of US and Japanese MNCs in Turkey.
Finds some evidence that MNCs have moved away from practices which have a long history in China (e.g. life-time employment and egalitarian pay) but in other areas they are still influenced by 'Chinese socialist ideology' (e.g. limited differences in pay between mgt and non-mgt).

On the basis that the differences between local and foreign-owned firms are not great, they claim that the country of origin effect is not strong.

The study finds that some practices can be implemented in Singapore (e.g. house unions) but others are "problematic for cultural reasons' (e.g. seniority wages).

The general finding is that there is a mix of global and local influences, mainly explained by cultural factors though with some references to 'non-cultural contexts'.

Uses Hofstede and other writers on culture to argue that MNCs are influenced by the national culture in their country of origin.

The paper establishes differences between the two groups of firms and attributes these to nationality, particularly the culture of the country of origin.

Foreign-owned firms more likely to use forms of numerical flexibility such as subcontractors and temporary employees.

Using a 'cultural values' approach it argues that Japanese practices are more suited to Turkey than are American ones. 
Table 1 (Continued)

\begin{tabular}{ll} 
Author(s) & Issue and method \\
\hline $\begin{array}{l}\text { Liberman and Torbiom } \\
(2000)\end{array}$ & $\begin{array}{l}\text { Explores variances and commonalities in } \\
\text { HR practice across an MNC based on } \\
\text { a case study of an MNC in eight countries. }\end{array}$
\end{tabular}

Paik et al. (2000)

Hannon el al. (1995)

Rosenzweig and Nohria (1994)

Khilji (2002)

Gamble (2003)

Schmitt and Sadowski (2003)

Tuselmann et al. (2003)

Yan (2003)
Extent of divergence or convergence of performance appraisal systems in MNCs based on a survey of foreign MNCs in Philippines, Indonesia. Malaysia and Thailand. The global-local issue in foreign MNCs in Taiwan based on a questionnaire survey of $100 \mathrm{MNCs}$.

Survey of foreign MNCs in the US.

Case studies of five foreign MNCs in Pakistan.

A case study of a British retail firm in China.

A survey of 297 British and American MNCs in Germany.

Survey of German MNCs in the north-west of England.

Survey of international joint ventures (JUVs) in eighty-seven cases in China.
Findings and comments

Concludes that 'variances are attributable to cultural factors, institutional pressures and other societal forces, and that commonalities might be explained by a common organizational culture'.

Finds significant divergences in the nature of appraisal systems and calls for these to be reflected in the approach of MNCs.

They go to some trouble to build up a range of global and local pressures and show how these affect HR practice.

Main finding was of relatively minor differences between the various nationalities of firm and local firms, implying widespread adaptation to local factors.

The author presents evidence showing that "both divergent and convergent issues act simultaneously, and hence are often complementary'.

Institutional and cultural features of the host environment better explain the nature of practices than country of origin influences,

The paper explains the balance between centralization and decentralization in terms of a 'rationalistic cost-minimization approach'.

The study provides no evidence of an attempt to transfer practices characteristic of Germany to their British subsidiaries though does 'point to a distinctive Germanic version of the "high road" ariant of the Anglo-Saxon approach'.

The study found little evidence of a clear national influence from the foreign parties to IJVs 
Table 1 (Continued)

\begin{tabular}{|c|c|c|}
\hline Author(s) & Issue and method & Findings and comments \\
\hline Law et al. (2004) & Survey of foreign MNCs in China. & $\begin{array}{l}\text { The paper details the extent and forms in which MNCs 'localize' } \\
\text { the management positions in their Chinese operations. }\end{array}$ \\
\hline
\end{tabular}


'can go in any direction' (1996: 996-7), not just from home to host countries. To operationalize this transfer of practices as part of a global element to management style, Kamoche (1996) advocates management transfers across business units as well as effective communication systems across these units. Kamoche claims that these practices serve as a 'glue' (1996: 239). That is, since managers can share knowledge from their experiences working at various subsidiaries, they become repositories of an integrated stock of knowledge that ranges the breadth and depth of the MNC. Thus, managers have some freedom to adapt HR practices at the local level, but their extensive MNC-based knowledge leads them to conform to a broadly uniform global IHRM strategy.

A different type of pressure for uniform HR practices globally arises from the legacy of the firm's embeddedness in its original national base. Whether or not there is a conscious attempt to 'export' the style and associated practices of the home country, the fact that key strategic decisions are taken there, largely by nationals of the home country, informs the behaviour of the firm at the international level. In many MNCs, this legacy creates a 'country of origin effect' that is carried over directly to the foreign subsidiaries partly through the deployment of expatriate staff in foreign subsidiaries. This influence from the national base of the firm, particularly the cultural influence, is commonly used in empirical studies as an explanation for the existence of global tendencies in IHRM. Many such studies argue that international policies in HR are based on those that are characteristic of the home country, leading MNCs to vary in terms of their approach to HRM by their country of origin (e.g. Bae et al., 1998; Faulkner et al., 2002; Ferner, 1997; Horwitz and Smith, 1998; Nam, 1995; Ngo et al., 1998; Paik and Teagarden, 1995). This is particularly evident in the vast literature on Japanese firms, but also shows up in the literature on US MNCs (Ferner et al., 2004).

In contrast, there are also a variety of grounds for expecting IHRM to reflect more local influences. Thus MNCs face pressures that lead them to decentralize decisionmaking on HRM issues to managers in their own national context, allowing the firm to respond to national peculiarities - the 'local' pressures. The most widely cited feature of countries that creates pressures for decentralization is national cultures; to operate effectively in a particular country, it is commonly argued, MNCs must be sensitive to the prevailing values and attitudes in that country. This is what Bartlett and Ghoshal (1998) refer to as the pressure for 'multi-culturalism'. Often referring to the work of Hofstede (1980) and Trompenaars (1993), many models argue that cultural differences between countries lead to a degree of 'differentiation' (Kamoche, 1996; Adler and Jelinek, 1986) in a firm's approach to IHRM.

A second source of pressure towards decentralizing decision-making on HR issues (i.e. the local end of the continuum) is the need to abide by national-level regulations and institutions in the labour market (e.g. Boxall, 1999). The diversity of legal regimes even within a region such as Europe, and the vast variations in the role and strength of labour market institutions across countries, lead MNCs to devolve responsibility for these issues to managers familiar with the national context. Brewster (1993), in reference to Europe, is a key example using this perspective. This sub-literature usefully involves a focus on host-country institutions (De Cieri and Dowling, 1999; Corteel and Le Blanc, 2001), but other writers have extended the logic to include the role of factors such as varying levels of economic and political predictability and stability and differing types of infrastructure as further forces towards localized HRM.

The empirical literature testifies to these 'local isomorphic' pressures (Ferner and Quintanilla, 1998). One method used in addressing this issue has been to compare foreign-owned firms with a control sample of local firms. Many of these studies point 
to important similarities between the two groups, commonly interpreted as evidence of adaptation to local circumstances by MNCs (e.g. Rozensweig and Nohria, 1994; Turner et al., 1997), though sometimes seen as evidence of local firms emulating the practices of MNCs (e.g. Geary and Roche, 2001). Another instance of this is Amante's (1995: 653) study of Japanese firms in the Philippines. in which he argues that most Japanese MNCs have not transferred many key features of the domestic HR system because of the "serious obstacles' to doing so (see also Amante, 1993; Gamble, 2003: Law et al., 2004: Paik et al., 2000; Shadur et al., 1995; Turner et al., 1997; Tuselmann et al., 2003; Yan, 2003).

A variety of authors argue for a middle way, a combination of the global and local pressures, in attempting to answer the question of how MNCs do (and should) manage their international workforces. McGaughey and De Cieri (1999) suggest that MNCs have a wide range of options in formulating IHRM policies. They claim that IHRM need not converge toward a corporate HRM norm but can diverge further and thereby become more localized over time. Schuler et al. (1993) and De Cieri and Dowling (1999) suggest that the tension between integration (consistency of HR practices in the MNC) and differentiation (local adaptation) is determined by a list of endogenous and exogenous factors, so many in fact that the models are difficult to operationalize.

Arguably, most empirical studies acknowledge that both global and local factors are in evidence. though the balance between the two differs across types of worker, with managers generally being subject to more standardized HR policies than nonmanagerial employees. The theme of the 'hybridization' of global and local influences is sometimes picked up explicitly, with it being argued that HR practice in MNCs is a balance of the two. For instance. Ding el al.'s (1997) study of foreign MNCs in China found that, while they had moved away from practices which have a long history in China, such as life-time employment and 'egalitarian pay', they are still influenced by what the authors term 'Chinese socialist ideology' in others, such as the limited differences in pay between managerial and non-managerial workers. The hybrid of global and local tendencies also comes through explicitly in a number of other studies (Farley et al., 2004: Gertson. 1990): Gill and Wong. 1998; Hannon et al., 1995; Khilji. 2002; Liberman and Torbiorn, 2000; Monks, 1996; Schmitt and Sadowski, 2003; Tayeb, 1994, 1998; Wasti. 1998).

In sum, the research into the global-local question has shed light on some important influences on the management of people in MNCs. The conceptual literature, for example, provides a range of reasons why both global and local pressures will be in evidence, and the empirical work highlights how these are felt in practice. However, there are a number of significant weaknesses and problems in this literature. We focus on three very important conceptual issues in turn. The first two of these relate to the way the global-local question has been addressed, while the third questions a central premise underpinning it,

\section{The inadequate conceptualization of national influences}

The first problem concerns the weaknesses in the way that national effects are conceptualized. Often the findings of empirical work are not located in a detailed account of the national systems of HRM in question. This is a particular problem in many studies of the "country of origin effect", as argued above. For example, Bird et al. (1998: 166) argue that some Japanese MNCs have undertaken a wholesale transplant of the HRM system from the parent company to the affiliate', yet do not describe the Japanese system in sufficient detail for this to be convincing. This problem is also evident in other 
studies, such as Ding et al.'s (1997) study of foreign MNCs in China. This failing to locate findings within a detailed account of national systems is also evident in consideration of the local pressures. Hannon et al.'s (1995) study of 100 foreign MNCs in Taiwan. for instance, tells us very little about the Taiwanese system of legal regulation of employment, the nature of key labour market institutions, dominant management styles in the country and so on.

Importantly, where there is an attempt to analyse a national system it is often couched in terms of culture. This can take two forms: either culture is used in a loose way to capture all aspects of national differences or use is made of a particular typology of culture, such as Hofstede's, Of course, aspects of national cultures vary markedly across countries and this is one important source of national differences in HR traditions and practices. However, the culturalist approach in general and the work of Hofstede in particular have been criticized on a number of grounds. such as McSweeney's (2002) critique of the empirical work contained in Culture's Consequences (Hofstede. 1980). Moreover. it is particularly difficult to tie cultural typologies to practical HR policy decisions for MNCs. For example. it is not clear whether compensation approaches should differ in countries where power distance is high versus countries where power distance is low or in countries which are more 'masculine' than 'feminine'. Apart from the utility for HR policy. perhaps the major problem with these cultural approaches, as Ferner and Quintanilla (2002) note, is that they explain relatively little. As the authors put it:

the emphasis of research has all too often been on a cut-price culturalism: simplistically explaining differences in outcomes across borders by references to some abstract free-floating notion of unchanging national 'cultural values' .... without inquiring further into the historically evolved institutional arrangements with which such "values" might be associated.

(Ferner and Qintanilla, 2002: 244)

Thus the cultural approach simply raises further questions. How, for example, did particular values and attitudes come to characterize a particular country? How can we account for change over time in these values and attitudes? And how do we account for the differences in cultures within nations? In sum, a widespread weakness of studies in this area is the weak explanatory power of the precise origins and nature of both global and local effects.

In the last few years an alternative approach has emerged in the field of IHRM that focuses on the key institutions within a nation (e.g. Almond et al., 2003: Saka, 2002). Institutionalist approaches are not new in other fields. For example, the societal effects' school used differences in national institutional frameworks to explain a range of differences between countries in such areas as company structures, skill levels and firm performance (e.g. Maurice et al.. 1980). More recently, the concept of a "national business system' has been used to provide a way of anchoring analysis within a convincing framework of national influences on HRM. A national business system has been defined as a set of interlocking structures and institutions in different spheres of economic and social life that combine to create a nationally distinct pattern of organizing economic activity (Whitley, 1999). This perspective sees 'differences in capitalist organization deriving from the national development paths pursued by different countries. and by the institutions that have been generated out of the interaction of social groups and classes (Ferner, 2000: 1).

The idea of a national business system is similar to Hall and Soskice's (2001) notion of 'institutional complementarities' within countries. These complementarities, they argue, lead 'nations with a particular type of co-ordination in one sphere of the economy .... to develop complementary practices in other spheres as well' (2001: 18). For instance, 
employment regulations designed to maximize job security are more compatible with financial systems in which ownership and capital provision are relatively stable. such as in Germany, but sit uneasily in systems in which corporate performance is assessed on current indices, such as share prices, and in which there is an active market in corporate control. A different example relates to the link between production strategies and industrial relations institutions. Firms are more likely to seek to compete on the basis of a workforce which has broad skills and is accorded significant autonomy to share information and engage in continuous improvement activities in systems in which industry-level collective bargaining equalizes wages for comparable occupational groups across firms, thereby making poaching more difficult. Conversely, in systems where interfirm labour mobility is high and unconstrained by industrial relations institutions, firms are likely to be reluctant to devote significant resources to training and development (see Hall and Soskice, 2001: 33-44).

Emphasizing the national aspect of business systems to capture international differences does not mean that this line of analysis need be blind to intra-national variations. Certainly, one of the weaknesses in the way national systems are conceptualized is that such variations within countries tend to be downplayed (although Bloom and Milkovich (1999) and Ortiz (2002) clearly allude to this). On close inspection it is evident that there is considerable internal diversity within most national economies 'sub-cultures' and regional differences - with this diversity being particularly marked in large countries. This internal diversity originates in part from regional forms of regulation. In the USA, for instance, a key source of variation is the existence of some 'right-to-work' states, such as many of those in the south, where it is much more difficult for unions to organize. A further example is that wages and working conditions vary considerably between Chinese provinces, while regional variations in HRM have been documented in a number of countries (see Bhattacherjee (2001) for an Indian example, Locke (1992) for an Italian one). The implication is that the pressures for local adaptation will vary within countries, particularly large, diverse nations like the USA. China and India, but even in smaller ones. The various institutional differences in the business environment between northern and southern Italy. for example. is well known. Nevertheless, despite some variations by region, the national level is useful as a conceptual tool, particularly when examining the role of institutions that affect HRM: national governments generally play a lead role in developing the framework of legal regulation of employment; key aspects of corporate law are defined at national level; structures governing the provision of training generally have common elements across an economy: and so on.

For MNCs, the lens of national business systems provides a way of assessing both the global and local pressures on MNCs. In relation to the former. we know that MNCs are deeply 'embedded' in their original business system across a range of dimensions: they raise finance disproportionately in the domestic capital markets: their shares are quoted principally on the domestic stock exchange and are owned mainly by domestic financial institutions and individuals; senior managerial positions are filled overwhelmingly by nationals of the parent country: R\&D is largely carried out in the firm 's original home base (e.g. Ruigrok and van Tulder. 1995). The strength of these roots in the original business system means that the strategies and actions of MNCs are shaped in significant ways by the key institutional features of this system. giving rise to a "country of origin" effect. In relation to the local pressures, the nature of labour market regulations varies significantly across countries, with the more regulated 'co-ordinated market economies" such as Germany presenting more significant constraints to firms than the more deregulated liberal market economies such as the USA. 
More generally, the national business systems approach provides for a focus on how cultures are embedded in wider societal structures, and how these give rise to prevailing norms within a system. Institutions set limits to what is feasible on the part of actors within organizations, and make some options more attractive than others. Thus they give rise to dominant patterns of behaviour that become established, thereby creating a context in which a set of values and attitudes emerge and endure. For instance, recent research has demonstrated that many US MNCs adopt international policies in the area of diversity, such as targets for women in management posts or a requirement that each subsidiary have a diversity council (Ferner et al., 2004: 373-8). This should not be seen as some inherent cultural trait of Americans but rather as stemming from the pressures created by the political and legal structures in the US, particularly the legacy of the civil rights movement and the financial penalties firms can incur if found guilty of discrimination. In this way, prevalent values and attitudes are embedded in national institutional frameworks. A focus on how nationally distinct institutions inform the behaviour of MNCs, therefore, promises to provide a much more convincing account of how both global and local effects than does a cultural values approach. However, to go too far in concentrating on institutional influences would risk falling into the trap of being deterministic. Therefore, this points to the need to consider the ways in which actors within MNCs use their individual 'agency' and the resources that they control to advance their own interests.

\section{The over-emphasis on structure and downplaying of organizational politics}

Given that structural forces do not have determining effects, it follows that there is a degree of space for organizational politics to shape the way MNCs manage their international workforces. For some writers, MNCs are loosely coupled political systems' (Forsgren, 1990). Yet, much research into the global-local question plays down the disputes and battles between actors at national or local level on the one hand and those at corporate level on the other. Consequently, many models and empirical studies fail to address the political nature of the global-local issue; it is political in that various groups of organizational actors will seek to either extend or limit the extent of global policies in order to defend or advance their own interests.

Kristensen and Zeitlin make this point succinctly: in their view, a multinational should be seen as 'a battlefield among subsidiaries representing and mobilising their own regional capabilities and national institutional means against the rest' (2001: 192). In a similar vein, Morgan et al. (2003) characterize the multinational as a 'transnational social space' which is 'inherently disordered', with global policies constituting one mechanism through which 'order is instilled'. Viewed from this perspective, the balance between global and local pressures is not the result of a one-off, rational calculation by top managers, but rather is something which is contested, over which there is an ongoing struggle, and consequently which shifts over time.

A strand of the IHRM literature does throw light on the political nature of the globallocal question. The way in which power relations shape the diffusion of organizational practices has been analysed by Ferner and Edwards (1995). Their framework categorized the varying sources of power within an organization and showed how the distribution of these shaped the negotiations between organizational groups. One source of power is derived from formal authority roles, but power can also be obtained from using the culture of the organization to legitimize certain courses of action and, most importantly perhaps, the control of resources of value to others within the organization. In MNCs the control of resources becomes a particularly important source of power since many assets 
that the organization possesses are strongly embedded in distinctive national contexts. Consequently, the ability of individuals and groups within MNCs to influence outcomes can be dependent on the nature of the national institutional frameworks within which they operate. In this way, institutions are far from being independent of intra-firm relations within MNCs, but rather can be a source of power that actors can mobilize (Geppert et al., 2003).

Thus many different groups within MNCs possess the scope to influence the way that global HR policies are developed and function. Actors at even relatively low levels within multinationals control resources which afford them some power in their relationships with higher levels of management, allowing them to adapt or circumvent corporate level policies. This is a theme of a number of studies of Japanese transplants in the UK, a particularly interesting context in which to investigate resistance given the concerted attempts that many Japanese MNCs have made to push novel practices to their foreign subsidiaries as a part of global policies. These studies have demonstrated the 'space' that actors at site level enjoy. For example, Webb and Palmer's (1998) ethnographic study of 'Telco' shed light on the way in which shopfloor workers found ways of 'evading surveillance' and of 'making time' for rest periods through both collective and individual means, thereby reducing the actual impact of practices introduced at the behest of corporate management. The opportunities to engage in 'fiddling' arose from management's incomplete control over their relations with suppliers, the temperamental technology and the difficulty and costs associated with monitoring the compliance of operators with standard operating procedures. Employees and their representatives may seek to block initiatives that are part of global integration in a more formal way, and, where initiatives are not blocked entirely, they may still be reinterpreted and consequently operate differently in a new environment (see, for example, Ortiz's (1998) discussion of team-working in GM in Spain).

Managers at local level may also look to block some corporate initiatives (sometimes without the knowledge of those at the HQ) where they see these as eroding their own influence or as clashing with the local system. The ability of workplace-level managers to defy directives from the HQ will be greater where corporate-level managers are dependent on them. Local managers may serve as crucial intermediaries between the firm and the local market since they possess knowledge about the national business system in question that outsiders do not. The literature on Japanese MNCs in the UK throws up examples of managerial resistance to global policies. For example, Broad (1994) charts the barriers that a Japanese firm had in transferring 'high involvement management' to its British site, focusing in particular on the reluctance of British managers to devolve responsibility to operators.

In contrast, actors at corporate HQ level may see global policies as a way of extending their influence and authority within the firm. In this way, global policies may not simply be a response to the competitive pressures or institutional influences on MNCs but may also be driven by the interests of a particular organizational group. A set of managers at the HQ may seek to legitimize the introduction of a particular global policy through developing a 'convincing discourse of change' (Martin and Beaumont, 2001: 1243).

This conception of the interaction between institutional forces and power relations within MNCs allows many of the weaknesses in the literature that were identified in the previous section to be overcome. It demands a focus on the politics of the global-local question - global policies issued from the corporate HQ can be ignored, manipulated or amended owing to the power of actors at lower levels, while the formation of these global policies cannot be simply read off from the extra-firm influences stemming from 
a national system. Since institutions are not seen as having determining effects, this approach suggests that, while institutional influences create general tendencies among MNCs, a range of possible courses of action are still feasible and the form these take is influenced by power relations within MNCs.

\section{The internal division of labour within MNCs}

While the first two points have indicated ways in which the global-local question could more usefully be conceptualized. the third questions whether it is always a sensible starting point in seeking to understand how MNCs operate.

Much of the literature on the global-local issue is not sensitive to the ways in which MNCs organize their processes of production and service provision internationally. An implicit assumption underpinning the global-local question is that all MNCs can derive benefits from standardizing HR policies; if they do not do so, it is because they have come up against local cultural or institutional constraints. This assumption may be justified for those MNCs that expand into other countries by constructing "mini-replicas" of existing operations. For such firms, building global HR policies is a part of the attempt to ensure that their HR practices across countries are consistent with, and contribute to, a global business strategy.

However, a relatively neglected strand of the literature demonstrates that in some other types of multinational the organization of international production or service provision does not create these pressures. Many MNCs have stratified their production processes across borders, carrying out quite distinct functions across countries (Marginson. 1994: Dedoussis, 1995). The location of a particular element of the process depends in part on the advantages that each national business system offers a firm given the characteristics of the function concerned. particularly its technological complexity and the degree to which it is labour intensive. Where the production or service provision process is stratified in this way. MNCs may derive little benefit from developing standard HR policies and are likely to see adaptation to local practices as their preferred option rather than something they submit to reluctantly.

A good illustration of this point is Wilkinson et al."s (2001) analysis of Japanese firms in Japan and Malaysia. On the face of it, one might expect the constraints posed by the Malaysian context to be a helpful way of looking at similarities and differences between employment practices in the two sets of plants. Factors such as the legal regulation of employment, the nature of employee representation. the cultural values of employees and skill levels of the workforce are all factors that may explain differences between the two countries. Wilkinson et al. (2001) did indeed find marked variations: the Japanese plants were characterized by job security, some autonomy for workers and opportunities for employees to undertake training and development; in contrast, jobs in the Malaysian plants were much less secure. monitoring of work was more notable and training was much more restricted. However. the authors explained these findings with reference not to national constraints but rather to the internal division of labour within the Japanese firms controlling the production processes. The domestic operations of the Japanese MNCs, which carried out the design and development roles that account for a significant proportion of the 'value added', deployed relatively complex technology that requires specialist knowledge and skills from employees. The HR practices that offered job security, a degree of autonomy and development opportunities for workers reflected management's attempt to operate with a stable and motivated workforce for this type of plant. The Malaysian units, on the other hand, carried out the more labour-intensive production work and used less specialist technology that can be operated by largely 
unskilled workers. The HR practices that meshed with this type of operation focused on cost minimization, with numerical flexibility, tight supervision and little in the way of training. Thus Wilkinson et al. (2001) explain the marked variations in employment practices between the two sets of plants in terms of this internal division of labour (see also Taylor, 2001).

This idea of segmented production or service provision is central to the notion of 'global commodity chains' (Gereffi, 1999) or global 'value chains' (Kaplinsky, 2001). Approaches using the notion of global chains emphasize that many products and services are provided through the co-ordination of a number of production units across borders with each unit performing a distinct function within the wider process. Co-ordination across these units in different countries is partly through ownership by MNCs and partly through international trade. The perspective is especially cognizant of the international segmentation of labour markets and the comparative advantage of different locations that makes it possible for MNCs to stratify their production or service provision processes so that different parts of the process take place in different countries. It sees MNCs as important drivers of new developments in the organization of production across borders, including a shift towards greater segmentation of production (see Humphrey (2000) for an excellent discussion of how the auto industry has changed in this fashion and see the work by Ernst (1997), Sturgeon (1997), Dedrick and Kraemer (1998), Borrus et al., (2000), Barnes and Kaplinsky (2000), Frenkel (2001), Gibbon (2001), Humphrey (2000), Gereffi (1999), Bair and Gereffi (2001), Schmitz and Knorringa (2000) for a range of other sectors).

This segmentation of production can occur across a range of firms, as in the apparel firms, like Nike and GAP, which do not own the factories directly, but control the chain through their buying power and marketing prowess (Gereffi refers to these as 'buyer driven' chains). This arm's-length control over a production process raises important questions for comparative researchers - for example, we know that in some chains in the apparel industry, even though brand name firms do not own production units, some HR practices are centrally determined for all of their subcontractors in all regions - but these are outside the scope of the global-local question as it is conventionally defined. Segmented international production can also occur across units owned by a multinational, as in the case of automotive manufacturers, which are at the node of a vertically integrated chain of factories that it directly owns (a 'producer-driven' chain). In this case, the segmentation of production means that the nature of technology employed and skills required in each of the multinational's sites differ markedly. This is clearly of direct relevance to the global-local question.

This spatial component of intra-firm chains draws attention to why a firm 'touch[es] down' in a specific geographic locale in the first place (Appelbaum and Gereffi, 1994). This is an important issue because MNCs choose locations for their various units based on a variety of factors - to access cheap labour, to use skilled labour, to bypass import restraints and thereby secure access to a market, to tap into technological expertise, to secure a reliable source of raw materials or components and so on - and the relative importance of these factors plays a key role in shaping the employment practices the firm employs for that site.

The segmentation of the production process in this way raises issues of power and dependence within the firm. Clearly, the HQ of a multinational has formal authority to develop global policies and issue specific instructions for sites. However, those units that perform functions that are difficult to transfer to other locations - because there are no or few other locations that provide the infrastructure and skills required for example, or because they have developed a stock of specialist knowledge and expertise in a particular 
part of the production process - possess countervailing power and may be able to defy the wishes of the parent firm without fear of sanction. In contrast, those units that compete fiercely with other sites for investment from the centre, or that face the threat of the work being relocated to an entirely new site, are more likely to have little alternative but to go along with the HQ's wishes. Some users of global chains as a concept have argued that the key or dominant agent will not have an unchallenged position (e.g. Raikes et al., 2000). Thus power can be diffused through a chain, so that not all subsidiaries within a chain will be completely subservient to the centre, particularly where they have developed distinctive 'subsidiary mandates' within the firm (Birkinshaw, 1996). The notion of distinctive roles for subsidiaries features in some of the writing on strategic management in MNCs (e.g. Hedlund, 1986).

It is this international division of labour that characterizes some, though not all, MNCs, which leads us to doubt whether the global-local question is always a sensible one to ask. MNCs which carry out quite different aspects of their production or service provision process across their various sites will have little incentive to develop standardized, global policies. It appears to be crucial, therefore, to locate the study of a unit's practices firmly in the context of the firm's international division of labour. The nature of this division plays a part in shaping the desirability, from senior managers' point of view, of having standard HR policies across the firm's operations.

\section{Conclusions and methodological implications}

In this paper we have focused on three concepts that address important weaknesses that have constrained research progress in the IHRM field. We do not see these concepts as constituting a model of the sort that abounds in the literature, but rather as concepts that can inform the nature of empirical work. These ideas have appeared in strands sometimes very minor strands - of the literature as we have indicated, but have not been systematically used in an integrated way in previous work.

Indeed, it is the inter-dependencies between the three concepts that we stress. We argue that these concepts should be integrated with each other rather than used in isolation. For instance, international 'chains' of production or service provision by definition straddle contrasting configurations of institutions, adapting to and taking advantage of the variety of systems in which they operate. Moreover, the way that such chains within MNCs function is shaped by the embeddedness of the controlling agent in a distinct national institutional setting that gives rise to a country of origin effect. The way that chains within MNCs operate will vary, therefore, according to the nationality of the parent firm (Whitley, 1996). National-level institutional configurations and international chains of production are thus strongly interlinked.

The inter-dependencies between organizational politics and national institutional frameworks are also evident. Institutions condition the behaviour of actors within MNCs as they do within all organizations, setting limits to what is feasible and attractive, but they do not close off all scope for choice; there remains a degree of 'space' for actors within institutional influences. Since the priorities and preferences of different groups of actors are bound to vary, the inevitable outcome is that courses of action will be shaped by the exercise of power within MNCs. In this context, the character and specificity of national institutions is one source of power that actors can use to advance their interests within a multinational. Moreover, the actions of large, powerful MNCs - the outcome of political processes within the firms, of course - can shape the nature of institutional frameworks themselves.

The functioning of international chains of operating units within MNCs and the nature of organizational politics are also interdependent. The role that each site plays within 
the internal division of labour is not determined solely by a rational assessment of those at the HQ but, rather, is strongly contested. The implications of the security and quality of jobs in each unit will depend fundamentally on its position within the chain, and therefore actors at site level will mobilize whatever resources are at their disposal in order to negotiate a favourable role for themselves. The creation and operation of chains of production are thus highly political in nature.

In sum. the contribution of this paper has been twofold. First, we have pointed to weaknesses in the way that the global-local question has been addressed and to concepts that have been used in either under-developed strands of the IHRM field or in related fields that can rectify these weaknesses. Second, we have stressed the connections between the institutional divides between countries, the organizational politics of MNCs and the international division of labour within them. These points have important implications for both practitioners and academics.

For practitioners, the ideas in this paper can serve as a tool with which they can question the balance between global and local dimensions to their HR policies. Managers in MNCs can seek to identify the logic of global policies - by examining the extent to which they help to secure benefits from co-ordinating and integrating their various units and in assisting in the learning of lessons across sites, for example - and the way these are balanced against local constraints. Perhaps more fundamentally, however, we have shown that practitioners should be aware of two additional factors: first, the highly political nature of the global-local issue: and, second, the way that the global-local issue is shaped by construction of the firm's international operations.

For academics, operationalizing these concepts has important methodological implications. For our understanding of the global-local question to be developed further through the use of the three concepts identified in this paper there is a need for intensive. collaborative research between teams in different countries. There are clearly several constraints to doing such research, however. One such barrier is the national differences in methodological training, with the quantitative, deductive and normative approach prevalent in HRM research in North America contrasting with a stronger qualitative. inductive, case-study-based research tradition in Europe. A second barrier concerns the monetary and time costs involved in such research. Despite these barriers, collaboration between teams of researchers in different countries could lead to both in-depth comparative case studies of MNCs, such as Belanger et al.'s (1999) study of ABB, and to genuinely comparable surveys. It seems that there is a need to develop the "invisible colleges" to which Pfeffer (1993) alludes, by which he means dense networks of researchers crossing university and national boundaries to solve problems. These colleges appear to exist to some extent in comparative industrial relations, but less so in international HRM. Where these emerge, collaborative research has the potential to play a key role in the theoretical development of what is a large but ultimately disappointing literature.

\section{References}

Adler, N, and Jelinek. M. (1986) 'Is Organization Culture Culture Bound?'. Human Resource Management, 25(1): 73-90.

Almond, P., Butler, P.. Clark. I., Colling. T.. Edwards, T., Ferner. A, and Holden. L. (2003) US Multinationals and the Management of Human Resources in Britain'. feedback report to participating companies. December, pp. 1-145.

Amante, M. (1993) 'Tensions in Industrial Democracy and HRM: A Case Study of a Japanese Enterprise in the Philippines:, International Journal of Human Resource Management. 4(1): $129-58$. 
Amante, M. (1995) Employment and Wage Practices of Japanese Firms in the Philippines: Convergence with Filipino-Chinese and Western-owned firms', International Journal of Human Ressurce Management. 6(3): 642-55.

Appelhaum. R. and Gereffi, G. (1994) 'Power and Profits in the Apparel Commodity Chain'. In Bonacich, E. et al. (eds) Global Production: The Apparel Industry in the Pacific Rim. Philadelphia. PA: Temple University Press.

Bae, J., Chen. S, and Lawler. J. (1998) 'Variations in HRM in Asian Countries: MNC Home Country and Host Country Effects', International Journal of Human Resource Management, 9(4): $653-70$.

Bair. J. and Gereffi. G. (2001) 'Local Clusters in Global Chains: The Causes and Consequences of Expor Dynamism in Torreon's Blue Jeans Industry'. World Development, 29(11): $1885-903$

Barnes, J. and Kaplinsky, R. (2000) Globalization and Trade Policy Reform: Whither the Automobile Components Sector in South Africa'. Competition and Change, 4(2): 211-43.

Bartlett. C. and Ghoshal, S. (1998) Managing Across Borders: The Transnational Solution to Managing Across Borders, 2nd edn. London: Hutchinson.

Belanger, J., Berggren, C.. Bjorkman, T. and Kohler. C. (1999) Being Local Worldwide: ABB and the Challenge of Global Management. Ithaca. NY: Cornell University Press.

Bhattacherjee. D. (2001) 'Trade Union and Industrial Relations in India', paper prepared for the ILO Conference on Trade Unions and Globalization held at the ILO, Geneva, 19-21 April.

Bird, A., Taylor, S. and Beechler, S. (1998) A Typology of Intemational Human Resource Management in Japanese Multinational Corporations: Organizational Implications'. Human Resource Management. 37(2): 159-72.

Birkinshaw, J. (1996) 'How Multinational Subsidiary Mandates are Gained and Lost', Journal of Intemational Business Studies. Third Quarter: 467-95.

Bloom, M. and Milkovich, G. (1999) 'An SHRM Perspective on International Compensation and Reward Systems', Research in Personnel and Human Resource Management, Supplement 4: $283-303$.

Borrus, M.. Ernst, D, and Haggard, S. (2600) International Production Networks in Asia. London and New York: Routledge.

Boxall. P. (1999) Human Resource Strategy and Industry Based Competition: A Conceptual Framework and Agenda for Theoretical Development'. Research in Personnel and Human Resource Management. Supplement 4: 259-81.

Brewster. C. (1993) 'Developing a European Model of Human Resource Management'. Intemational Journal of Human Resource Management. 4(4): 765-85.

Broad. G. (1994) 'The Managerial Limits to Japanization: A Manufacturing Case Study', Human Resource Management Joumal, 4(3): 52-69.

Buckley. P. and Casson. M. (1976) The Future of the Multinational Enterprise. London: Macmillan.

Clark, T., Gospel, H. and Montgomery. J. (1999) Running on the Spot? A Review of Twenty Years of Research on the Management of Human resources in Comparative and International Perspective'. Imernational Journal of Human Resource Management, 10(3): 520-44.

Corteel, D. and Le Blanc. G. (2001) The Importance of the National Issue in Cross-border Mergers', paper presented to a conference entitled 'Cross-Border Mergers and Employec Participation in Europe, École des Mines, Paris, 9 March.

De Cieri, H. and Dowling. P. (1999) 'Strategic Human Resource Management in Multinational Enterprises: Theoretical and Empirical Developments'. Research in Personnel and Human Resource Management, Supplement 4: 305-27.

Dedoussis. V. (1995) 'Simply a Question of Cultural Barriers? The Search for New Perspectives in the Transfer of Japanese Management Practices'. Journal of Management Studies, 32(6): $731-45$.

Dedrick, J, and Kraemer. K. (1998) Asia's Computer Challenge: Threat or Opportunity for the United States and the World. Oxford: Oxford University Press. 
Ding, D. Fields, D, and Akhtar, S. (1997) 'An Empirical Study of HRM Policies and Practices in Foreign-invested enterprises in China: The case of Shenzen Special Economic Zone'. International Journal of Human Resource Management, 8(5): 595-613.

Ernst, D. (1997) 'From Partial to Systemic Globalization: International Production Networks in the Electronics Industry' Berkeley Reundtable on the Imternational Economy; Working paper 98.

Farley. J., Hoenig, S. and Yang, J. (2004) 'Key Factors Influencing HRM Practices of Overseas Subsidiaries in China's Transition Economy'. International Journal of Human Resource Management, 15(4/5): $688-704$.

Faulkner. D., Pitkethly, R. and Child, J. (2002) International Mergers and acquisitions in the UK 1985-1994: A Comparison of National HRM Practices', International Journal of Human Resource Management, 13(1): 106-22.

Ferner. A. (1997) Country of Origin Effects and HRM in Multinational Companies:. Human Resource Management Journal. 7(1): 19-37.

Ferner. A. (2000) The Embeddedness of US Multinational Companies in the US Business System: Implications for HR/IR: DMU Business School Occasional Papers.

Ferner. A. and Edwards. P. (1995) Power and the Diffusion of Organisational Change in Multinational Companies', European Journal of Industrial Relations, 1(2): 229-57.

Ferner. A. and Quintanilla, J. (1998) Multinationals National Business Systems and HRM: The Enduring Influence of National Identity or a Process of "Anglo-Saxonization".. International tournal of Human Resource Management, 9(4): 710-31.

Ferner. A and Quintanilla, J. (2002) 'Between Globalization and Capitalist Variety: Multinationals and the International Diffusion of Employment Relations', European Jeumal of Industrial Relations. 8(3): 243-50.

Ferner. A.. Almond. P.. Clark, I.. Colling, T.. Edwards, T.. Holden, L. and Muller, M. (2004) The Dynamics of Central Control: Transmission and Adaptation of "American" Traits in US Multinationals Abroad: Case Study Evidence from the UK'. Organization Studies; 25(3): 363-91.

Forsgren. M. (1990) 'Managing the International Multi-Centre Firm'. European Management Journal, $8(2): 261-7$.

Frenkel, S. (2001) Globalization Athletic Footwear Commodity Chains and Employment Relations in China , Organization Sudies, 22(4): 531-62.

Gamble. J. (2003) Transferring Human Resource Practices from the United Kingdom to China: The Limits and Potential for Convergence', International Journal of Human Resource Management. 14(3): 369-87,

Geary. J. and Roche. W. (2001) Multinationals and Human Resource Practices in Ireland: A Rejection of the "New Conformance Thesis". International Journal of Human Resource Management, 12(1): 109-27.

Geppert, M., Williams, K. and Matten. D. (2003) 'The Social Construction of Contextual Rationalities in MNCs: An Anglo-German Comparison of Subsidiary Choice'. Joumal of Management Studies, 40(3): $617-40$.

Gereffi. G. (1999) 'International Trade and Industrial Upgrading in the Apparel Commodity Chain: Journal of International Economics, 48: 37-70.

Gertson. M. (1990) 'Intercultural Competence and Expatriates'. Imernational Journal of Human Resource Management, 1(1): 341-62.

Gibbon. P. (2001) 'Upgrading Primary Products: A Global Value Chain Approach'. Werld Development. 29(2): 345-63.

Gill, R. and Wong. A. (1998) The Cross-Cultural Transfer of Management Practices: The Case of Japanese HRM Practices in Singapore', International, Journal of Human Resource Management. 9(1): $116-35$.

Hall. P. and Soskice. D. (2001) 'An Introduction to Varieties of Capitalism'. In Hall. P. and Soskice. D. (eds) Varieties of Capitalism: The Institutional Foundations of Comparative Advantage. Oxford: Oxford University Press, pp. 1-68.

Hannon. J., Huang, I. and Jaw, B. (1995) International Human Resource Strategy and its Determinants: The Case of Subsidiaries in Taiwan', Joumal of International Business Studies. 26(3): $531-48$. 
Hedlund, G. (1986) 'The Hypermodern MNC', Human Resource Management, 25(Spring), 9-36. Hofstede, G. (1980) Culture's Consequences. Thousand Oaks, CA: Sage.

Horwitz, F. and Smith, D. (1998) 'Flexible Work Practices and HRM: A Comparison of South African and Foreign-owned Companies', International Journal of Human Resource Management, 9(4): 590-607.

Humphrey, J. (2000) 'Assembler-Supplier Relations in the Auto Industry: Globalization and National Development', Competition and Change, 4(3): 245-71.

Kamoche, K. (1996) 'The Integration-Differentiation Puzzle: A Resource-Capability Perspective in International Human Resource Management', International Journal of Human Resource Management, 7(1): 230-44.

Kaplinsky, R. (2001) The Value of Value Chains: Spreading the Gains from Globalisation. University of Sussex: International Development Studies.

Khilji. S. (2002) 'Modes of Convergence and Divergence: An Integrative View of Multinational Practices in Pakistan', International Journal of Human Resource Management, 13(2): 232-53.

Kristensen, P. and Zeitlin, J. (2001) 'The Making of a Global Firm: Local Pathways to Multinational Enterprise', In Morgan, G., Kristensen, P. and Whitley, R. (eds) The Multinational Firm: Organizing Across Institutional and National Divides. Oxford: Oxford University Press.

Law, K., Wong, C. and Wang, K. (2004) 'An Empirical Test of the Model on Managing the Localization of Human Resources in the People's Republic of China', International Journal of Human Resource Management, 15(4-5): 635-48.

Liberman, L. and Torbiorn, I. (2000) 'Variances in Staff-Related Management Practices at Eight European Country Subsidiaries of a Global Firm', International Journal of Human Resource Management, 11(1): 37-59.

Locke, R. (1992) 'The Demise of the National Union in Italy: Lessons for Comparative Industrial Relations Theory', Industrial \& Labor Relations Review, 45(2): 229-49.

McGaughey, S.L. and De Cieri, H. (1999) 'Reassessment of Convergence and Divergence Dynamics: Implications for International HRM', International Journal of Human Resource Management, 10(2): 235-50.

MeSweeney, B. (2002) 'Hofstede's Model of National Cultural Differences and their Consequences: A Triumph of Faith - a Failure of Analysis', Human Relations, 55(1): $89-118$.

Marginson, P. (1994) 'Multinational Britain: Employment and Work in an Internationalised Economy', Human Resource Management Journal, 4(4): 63-80.

Martin, G. and Beaumont, P. (2001) 'Transforming Multinational Enterprises: Towards a Process Model of Strategic Human Resource Management Change', International Journal of Human Resource Management, 12(8): 1234-50.

Maurice, M., Sorge, A. and Warner, M. (1980) 'Societal Differences in Organizing Manufacturing Units', Organization Studies, 1: 59-86.

Monks, K. (1996) 'Global or Local? HRM in the Multinational Company: The Irish Experience', International Journal of Human Resource Management, 7(3): 721-35.

Morgan, G., Kelly, B., Sharpe, D. and Whitley, R. (2003) 'Global Managers and Japanese Multinationals: Internationalization and Management in Japanese Financial Institutions', International Journal of Human Resource Management, 14(3): 389-407.

Nam, S. (1995) 'Culture, Control and Commitment in UVs', International Journal of Human Resource Management, 6(3): 553-67.

Ngo, H., Turban, D., Lau, C. and Lui, S. (1998) 'Human Resource Practices and Firm Performance of MNCs: Influence of Country of Origin', International Journal of Human Resource Management, 9(4): 632-52.

Ortiz, L. (1998) 'Unions' Response to Teamwork: The Case of Opel Spain', Industrial Relations Journal, 29(1): 42-57.

Ortiz, L. (2002) 'The Resilience of a Company-level System of Industrial Relations: Union Responses to Teamwork in Renault's Spanish Subsidiary', European Journal of Industrial Relations, 8(3): 277-99. 
Paik. Y. and Teagarden, M. (1995) 'Strategic HRM Approaches in the Maquiladora Industry: A Comparison of Japanese, Korean and US Firms', International Journal of Human Resource Management, 6(3): 568-87.

Paik. Y., Vance. C. and Stage. H. (2000) 'A Test of Assumed Cluster Homogeneity for Performance Appraisal Management in Four South-East Asian countries', International Journal of Human Resource Management. 11(4): 736-50.

Pfeffer, J. (1993) 'Barriers to the Advancement of Organizational Science: Paradigm Development as a Dependent Variable', Academy of Management Review. 18(4): 599-620.

Raikes. P.. Jensen. M. and Ponte, S. (2000) 'Global Commodity Chain Analysis and the French Filiere Approach: Comparison and Critique'. Economy and Societv, 29(3): 390-417

Rosenzweig, P. and Nohria, N. (1994) 'Influences on Human Resource Management Practices in Multinational Corporations:, Journal of International Business Studies, Second Quarter, $229-51$.

Ruigrok, W. and Tulder. R. van (1995) The Logic of International Restructuring. London: Routledge.

Saka, A. (2002) 'Institutional Limits to the Internalization of Work Systems: A Comparative Study of Three Japanese Multinational Companies in the UK', European Journal of Industrial Relations, $8(3): 251-75$.

Schmitt. M. and Sadowski. D, (2003) 'A Cost-minimization Approach to the International Transfer of HRM/IR Practices: Anglo-Saxon Multinationals in the Federal Republic of Germany'. International Journal of Human Resource Management. 14(3): 409-30.

Schmitz. H. and Knorringa, P. (2000) 'Learning from Global Buyers'. Journal of Development Studies, 37(2): 177-205.

Schuler. R.. Dowling. P. and De Cieri. H. (1993) An Integrative Framework of Strategic International Human Resource Management', Journal of Management. 19(2): $419-59$.

Shadur. M., Rodwell, J. and Bamber. G. (1995) 'The Adoption of International Best Practices in a Western Culture: East meets West'. International Journal of Human Resource Management. 6(3): $735-57$.

Sturgeon, T. (1997) Turnkey Production Networks: A New American Model of Industrial Organization?'. Berkeley Roundtable on the International Economy. Working Paper 92A.

Tayeb, M. (1994) 'Japanese Managers and British Culture: A Comparative Case Study'. Intemational Journal of Human Resource Management, 5(1): 145-66.

Tayeb, M. (1998) 'Transfer of HRM Practices across Cultures: An American Company in Scotland', International Journal of Human Resource Management, 9(2): 332-58.

Taylor, B. (2001) 'The Management of Labour in Japanese Manufacturing Plants in China'. International tournal of Human Resource Management, 12(4): 601-20.

Taylor, S., Beechler, S. and Napier. N. (1996) 'Towards an Integrative Model of Strategic International Human Resource Management'. Academy of Management Review, 21(4): 959-85.

Trompenaars, F. (1993) Riding the Waves of Culture. London: Economist Books.

Turner. T.. D'Art, D. and Gunnigle, P. (1997) 'Pluralism in Retreat? A Comparison of Irish and Multinational Manufacturing Companies', International Journal of Human Resource Management, 8(6): 825-40.

Tuselmann. H.. McDonald. F. and Heise. A. (2003) 'Employee Relations in German Multinationals in an Anglo-Saxon Setting: Toward a Germanic Version of the Anglo-Saxon Approach'. European Journal of Industrial Relations, 9(3): 327-49.

Wasti, S. (1998) 'Cultural barriers in the Transferability of Japanese and American HR Practices in Developing Countries: The Turkish Case', Intemational Journal of Human Resource Management, 9(4): 608-31.

Webb. M. and Palmer, G. (1998) 'Evading Surveillance and Making Time: An Ethnographic View of the Japanese Factory Floor in Britain', British Journal of Industrial Relations, 36(4): 611 - 27.

Whitley, R. (1996) 'Business Systems and Global Commodity Chains: Competing or Complementary Forms of Economic Organisation , Competition and Change, 1: 411-25. 
Whitley, R. (1999) Divergent Capitalisms: The Social Structuring and Change of Business Systems. Oxford: Oxford University Press.

Wilkinson, B., Gamble, J., Humphrey, J., Morris, J. and Anthony, D. (2001) 'The New International Division of Labour in Asian Electronics: Work Organization and Human Resources in Japan and Malaysia', Journal of Management Studies, 38(5): 675-95.

Yan, Y. (2003) 'A Comparative Study of Human Resource Management Practices in International Joint Ventures: The Impact of National Origin', International Journal of Human Resource Management, 14(4): 487-510. 